\title{
Acervos etnológicos e curadoria científica: o contraponto da arqueologia'
}

\author{
Maria Isabel D'Agostino Fleming ${ }^{2}$
}

\section{Introdução}

Como debatedora da mesa sobre acervos etnológicos e curadoria científica, levantei alguns pontos abordados pelos colegas nas suas comunicações que tratam de aspectos que também fazem parte dos encaminhamentos e preocupações da pesquisa arqueológica, especialmente as pesquisas com coleções. Assim, minhas observações estão divididas em cinco itens: 1) as críticas pós-modernas às pesquisas com orientação colonialista: a arqueologia do Império romano; 2) os museus antropológicos como ferramenta de pesquisa: o prolongamento do trabalho de campo; 3 ) documentação: pesquisa de campo e arquivos; 4) processo curatorial e suas articulações no espaço museológico; 5) conclusão.

\section{As críticas pós-modernas às pesquisas com orientação colonialista: a arqueologia do Império romano}

A pesquisa arqueológica nesta área é um exemplo emblemático por três razões: $\mathbf{o}$ objeto de estudo é modelo das ações coloniais; ao

1 Trabalho apresentado na Mesa 2: Acervos etnológicos e curadoria científica

2 Arqueóloga da área de Arqueologia Clássica. Programa de Pós-Graduação em Arqueologia. Museu de Arqueologia e Etnologia. Universidade de São Paulo mesmo tempo, Roma é vista como elemento relevante na formação das raízes dos países colonizadores e, finalmente, é uma pesquisa que tem uma relação direta com a formação das coleções arqueológicas

Genericamente falando, e em especial no que respeita as áreas do Ocidente mediterrânico, o discurso dominante nos estudos sobre as províncias romanas tem um fundamento filosófico que é o modelo de romanização progressiva, o qual propõe "uma mudança gradual, cumulativa e direcional de um extremo a outro, do modo de existência nativo ao romano. A perspectiva progressiva atribui um sentimento pró-romano à elite social provincial. Com base na evidência material, este $e$ thos pró-romano é estendido à maior parte do resto da população" (HINGLEY, 1997: 82)

Esta perspectiva está em total descompasso com os estudos pós-coloniais voltados para os povos da periferia de impérios ocidentais recentes (sécs. XIX e XX). Esses estudos identificam relatos de vozes alternativas das populações dominadas e sugerem que os povos da periferia dos impérios ocidentais tinham uma gama de visões que foram ignoradas e suprimidas pelos centros imperiais. No caso da dominação romana, a dificuldade de fazer uma idéia de como as populações locais sentiam-se sobre a conquista romana e seu controle vem da ausência de vozes nativas na literatura clássica e ausência de textos nativos. Tendo em mente esta diretriz, no caso das áreas provinciais romanas, para que tenhamos o alcance dos problemas que abordagens mais críticas enfrentam na procura de uma variedade de visões locais sobre Roma e a conquista romana, devemos nos voltar, ainda que rapidamente, para a raiz mesma desses problemas e considerar o histórico da pesquisa tradicional imperialista/colonialista da Europa ocidental do final do séc. XIX até meados do séc. 
XX. Neste histórico se alternam abordagens da presença romana nos próprios países europeus (principalmente França, Inglaterra e Itália) e nas áreas coloniais, especialmente a África. O fio condutor era o Império romano como modelo e justificativa de ações internas para esses países, sobretudo a Inglaterra, que detinha o maior império do Ocidente moderno.

Um exemplo de arqueologia colonial é a afirmação de J. Toutain, arqueólogo francês das primeiras décadas do séc. XX, "Quanto melhor compreendermos o que os romanos realizaram em suas províncias da África, mais seremos capazes de dirigir nossos esforços e mais rapidamente assegurar seu sucesso" (apud M. BOUCHENAKI, 1978: 9).

Apesar de uma visão crítica de alguns atuais arqueólogos do mundo romano, relativa ao contexto da arqueologia colonialista, como T.W. POTTER (1987), o foco passa ao largo do problema. Em geral, são críticas de um misto metodológico-político sem que se atente para o uso que foi feito da cultura material acumulada na explicação da presença romana nas províncias. É aceita a idéia de que a prática desta arqueologia permitiu criar um enorme corpus de dados, especialmente epigráficos; uma série de sítios escavados que proporcionaram uma visão surpreendente sobre a vida da cidade antiga; e, acima de tudo, uma poderosa consciência pública sobre o passado romano. Esta é a realidade de grande parte das coleções e da enorme dificuldade que apresentam. $O$ problema é que houve uma negligência com elementos indígenas, especialmente no norte da África, área colonial francesa, onde as fazendas foram em grande parte sacrificadas em favor de cidades romanas limpas, isoladas. Ainda se sabe muito pouco da contribuição indígena e dos sítios menos romanizados. O norte da África foi visto quase que exclusivamente sob um ponto de vista romano, até bem recentemente.

Esta negligência com elementos indígenas pode ser identificada também na Itália, onde apenas em tempos relativamente recentes os chamados povos itálicos (isto é, não romanos, etruscos ou gregos) começaram a receber a devida atenção. Mais de 40 línguas eram faladas na Península Itálica antes da unificação romana e é correto examinar o papel deste mosaico complexo de povos na formação do primeiro estado internacional do mundo ${ }^{3}$. No território francês, o conceito de uma cultura não romana, mas galo-romana, foi estabelecido em um estágio re-

$3 \quad \mathrm{Na} 1^{\mathrm{a}}$ Idade do Ferro começam diferenciações relevantes entre culturas. Formam-se grandes contornos de grandes agrupamentos étnico-lingüísticos. Nos séculos seguintes, esses agrupamentos serão mais bem definidos, em primeiro lugar, pela introdução da escrita em grande parte da Península Itálica e, em segundo lugar, graças à documentação literária grega em termos etnográficos, sobretudo com Hesíodo e Heródoto. Nas regiões mais desenvolvidas, o processo de diferenciação social é acompanhado pelo processo de materialização das diferenças étnicas. Quanto mais elevada é a taxa de desenvolvimento em cada zona, mais aguda e evidente é essa diferença, a qual é traduzida por um fenômeno de natureza material e ideológica. No aspecto material, de um lado, há um grupo de culturas diversificadas, de outro, há uma homogeneidade interna dessas culturas, nas formas produtivas, na homogeneidade das relações sociais de produção próprias e na homogeneidade das relações de troca. $\mathrm{O}$ aspecto ideológico é proporcionado pelo grau de consciência étnica que freqüentemente é acompanhado pela emergência de uma superioridade econômica e militar. Devido a esses fatores, não é por acaso que os círculos culturais mais antigos reconhecíveis coincidam com os grupos étnicos do período histórico que, no momento, estavam no mais alto grau de desenvolvimento: em primeiro lugar, os etruscos, cuja forma cultural entre a proto-história e a história é a vilanoviana; em seguida, os latinos, que desde um período muito antigo exprimem uma cultura material própria conhecida como lacial, ainda que fortemente influenciada pela cultura vilanoviana vizinha. No resto da Península Itálica observa-se o reverso deste fenômeno, que é quase imediato nas áreas menos desenvolvidas e que tem uma relação direta e proporcional com o grau de articulação social alcançado em cada área - ou seja, esta articulação é inversamente proporcional ao grau de subdesenvolvimento. 
lativamente precoce entre os eruditos modernos. Havia o grande herói gaulês Vercingetórix. $\mathrm{O}$ elemento celta na Gália Romana foi rapidamente definido, especialmente no campo da arte e da religião, conforme atestam as inúmeras publicações sobre estes temas e especificamente sobre as imagens que representam o Casamento Divino, uma associação de divindades gaulesas femininas e deuses romanos.

Quanto à avaliação da arqueologia romana na Inglaterra, numa visão mais conservadora, se atribui a este país o estabelecimento de bases ainda mais seguras para uma apreciação adequada da natureza da cultura romana provincial. Neste âmbito, foi significativa a contribuição dos antiquários do séc. XIX, com coleções extraordinárias de material romano-britânico, vendido ao British Museum em 1856, especialmente cerâmica. A apreciação da contribuição da cultura romana à formação cultural britânica combinava a evidência da literatura antiga, a epigrafia e a arqueologia.

\section{Os museus antropológicos como ferramenta de pesquisa: 0 prolongamento do trabalho de campo}

É nesta interação entre o trabalho de campo e a pesquisa de coleções arqueológicas que se insere a procura de um conhecimento mais sólido. É a compreensão mesma da formação de coleções arqueológicas com vistas ao seu aproveitamento científico.

\section{A formação de coleções}

Tendo em vista as considerações acima sobre o caráter da pesquisa arqueológica de cunho colonialista até bem recentemente, é fundamental abordar a natureza das coleções formadas com tais características, numa tentativa de um aproveitamento científico das mesmas.

Sabe-se que na maior parte das vezes, a casualidade é que regeu a formação das co- leções. E essa casualidade, indiretamente, pode contribuir para nosso estudo.

As coleções muitas vezes apresentam séries de objetos que no período de sua formação, pelo fato de serem séries, tomaram uma identidade, um corpo, um volume que se impôs e que se configuraram como um dado cultural também naquela época. Essas séries não puderam ser ignoradas por aqueles colecionadores. É um dado cultural latente. Ainda que o objetivo fosse predominantemente estético, essas grandes quantidades de objetos, com as mesmas características, pelo menos serviam para os antigos como uma prova da capacidade de realizações, ou de um nível técnico desenvolvido.

A grosso modo, há dois tipos de coleções:

1. de valor estético apenas: objetos belos, ainda que de utilização comum, mas não repetitivos. A coleção que ainda hoje se faz. Objetos exóticos de lugares e culturas diferentes. A importância mesma desse tipo de coleção está no fato de que esses objetos não se repetem e, por isso mesmo, adquirem maior valor: o sentido do único contraposto ao repetitivo.

2. séries de objetos mais ou menos belos para os padrões antigos. Neste caso, pense-se que o colecionismo acabou atingindo esses objetos já que os mais belos não são inesgotáveis, e também no séc. XIX vimos que já havia uma mudança na mentalidade quanto ao que colecionar, pensandose no dado cultural.

Ainda com essas informaçōes, permanece a questão: como se justifica trabalhar com coleções numa época em que se preconiza o rigor na escavação?

$1^{\circ}$. Não se pode ignorar nem desprezar a enorme quantidade de material arqueológico existente desde o período em que se começou a colecionar.

$2^{\circ}$. O fato de existirem escavações rigorosas hoje em dia, exatamente, possibilita muitas vezes dar um sentido a peças que antes eram quase que sem identidade, sem uma histó- 
ria, sem um valor cultural (resumindo, estavam fora de seu contexto - isso soa meio temerário diante das críticas sobre a descontextualização das coleções) [Fabian (2004), por exemplo, o significado estético e científico (ocidental, portanto) dos objetos indígenas estão prejudicados justamente no fato mesmo de sua descontextualização].

Por exemplo: nas escavações podem ser encontradas séries que completam os dados que faltam para a peça.

$3^{\circ}$. Ao mesmo tempo, desde que possível alguma datação, ou o estabelecimento de um contexto para a peça de coleção, ela pode ser um dado valioso e pode completar algumas lacunas na informação arqueológica.

Não vou estender-me mais nos detalhes dos procedimentos. De qualquer forma, este deve ser o encaminhamento para que se chegue mais próximo de resultados mais significativos na busca do conhecimento das sociedades representadas nessas coleções.

\section{Documentação: pesquisa de campo e arquivos}

Além do que foi observado sobre a formação de coleções, no caso de coleções arqueológicas provenientes de pesquisa de campo, deve ser considerado o registro da documentação numa perspectiva histórica, isto é, nesse registro é clara a hierarquização dos objetos em função da época em que se deu a pesquisa: as descrições são sumárias ou às vezes ausentes para categorias de objetos "não nobres" o que se aplica também à quantificação dos mesmos, extremamente irregular. São exemplo as coleções formadas no séc. XIX e que se encontram espalhadas pelos museus na Europa e Américas: as fichas contêm informações precárias seja do número de peças quanto de sua discriminação, caso se trate de vasos cerâmicos, estatuetas ou outros objetos provenientes de áreas de escavação parcamente especificadas.

\section{Processo curatorial e suas articulações no espaço museológico}

Quanto ao processo curatorial, apenas um museu de natureza e caráter universitário pode oferecer a "oportunidade de realizar um enfoque articulado como proposto na curadoria da coleção Xikrin" e outros exemplos semelhantes, conforme esquematizo na figura abaixo.

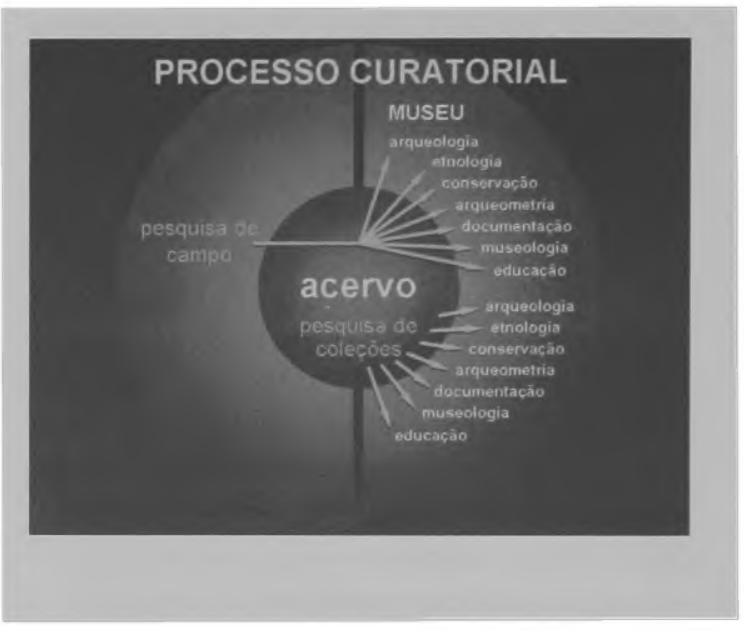

\section{Conclusão}

Se hoje a história e a cultura material são valorizadas pela antropologia, na arqueologia esta é uma relação imperativa que envolve a pesquisa de campo e pesquisa documental. Evidentemente, é impossível a situação ideal da presença de indígenas na curadoria de coleções arqueológicas, como nos casos apresentados nesta mesa e outros muito interessantes, por exemplo, a pesquisa publicada nos números $15,16-17$ da Revista do Museu de Arqueologia e Etnologia: "Perspectivas recentes para a curadoria de coleções etnográficas" e "Conservação preventiva, intervenção e restauro em acervo etnológico: sugestões metodológicas" (Aivone Carvalho; Dulcília Lúcia de Oliveira Silva; Gedley Belchior Braga e outros). A pesquisa trata das possibilidades de diálogos multifocais entre os etnólogos, os conservadores e os 
povos indígenas brasileiros. Abordam-se desde a experiência de repatriação de uma pequena coleção etnográfica Bororo - que pertencia ao Museu Missionário Colle Don Bosco, na Itália - para a aldeia Meruri, até a realização de um workshop de conservação - no Museu Dom Bosco de Campo Grande - com a presença de representantes profissionais de diversas especialidades, incluindo indígenas de alguns grupos brasileiros. No caso da curadoria de coleções arqueológicas, pode-se tentar minimizar esta grande desvantagem com os resultados de pesquisas de campo mais sistemáticas que indiquem variações e a dinâmica própria das sociedades estudadas.

\section{Bibliografia:}

BOUCHENAKI, J.M. Cités antiques d'Algérie. Algers: Art et Culture,1978.

HINGLEY, R. Resistance and domination in Roman Britain. In Mattingly, D.J. (Ed.) Dialogues in Roman Imperialism. Power, discourse, and discrepant experience inthe Roman Empire. Journal of Roman Archaeology. Supplementary Series Number 23. Portsmouth, Rhode Island, p. 81-100. 1997

POTTER, T.W. The Institute and Roman Archaeology: Past, Present and Future - An Outsider's View. Bulletin of the Institute of Archaeology, v. 24, suppl., p. 71-84. 1987. 